\title{
JUAN AMOS COMENIO: CONCEPTO Y NATURALEZA DE LA PEDAGOGÍA
}

Lic. Ana Mara Gutiérrez Huby*

\section{RESUMEN}

En la obra Páginas Escogidas sobre los escritos de J.A. Comenio, afirma Piaget que el sistema de Educación propuesto por Comenio es universalista, a pesar de estar desarrollado en el contexto del siglo XVIII, porque está dirigido a todos los hombres sin diferencia de condición social o económica, de religión, de raza, o nacionalidad y resalta que requiere que se extienda a todos los pueblos por más subdesarrollados que éstos sean.

Es en todos sus escritos que Comenio lejos de presentar simples teorías inicia todo sus proyectos con una filosofía teórica, histórica y político-social no superada aún.

Con Comenio tenemos entonces el proyecto del surgimiento de nuevos valores y de cómo ellos se proponían soportar la modernidad.

Es por ello que Comenio no se cansaría de formular proyectos de paz universal; llevando a cabo el «Collegium Lucis", es decir, el antecedente propio de la UNESCO pero como órgano ejecutor o Ministerio de Educación Internacional.

Para dar inicio al tema siempre es bueno remitirnos a la génesis de los que hicieron posible su creación.

Hablar de Juan Amos Comenio es hablar de la Europa renacentista de los siglos XVI y XVII y de uno de sus más brillantes autores; pero del cual nunca hemos oído que se le trate merecidamente como uno de los padres de la pedagogía moderna, ya que con su obra Didáctica Magna, contribuyó a crear una ciencia de la educación y una técnica de la enseñanza que coloca al alumno como centro del fenómeno educativo, haciendo que todo concurra a su servicio: maestros, textos, aulas y métodos.

Comenio parte del convencimiento de que el hombre sólo necesita una educación adecuada para desarrollar su naturaleza a plenitud; es decir, que el hombre por su naturaleza no necesita tomar nada del exterior sino que es preciso tan sólo desarrollar lo que encierra oculto en sí mismo y señala claramente la intervención de cada uno de sus elementos. Con esta concepción, proclama claramente que todos los hombres tienen una aptitud innata hacia el conocimiento y no se restringe éste a sólo una élite o para algunos iluminados, creándose la concepción de una escuela popular de gran cubrimiento y la que todos tienen acceso.

Las ideas educativas de Comenio transforman a la pedagogía en ciencia de la educación y provoca que los pedagogos se conviertan -de simples ayos que eran- en profesionales de la educación.

Fue promotor del desarrollo de la comunidad ya que se preocupa por elevar el nivel económico del pueblo, no limitando su acción educativa al recinto

* Docente Asociada de la Facultad de Ciencias Contables. 
de la escuela, sino haciéndola llegar a todo el ámbito de la comunidad. Entre sus méritos destaca ser el precursor de los jardines de niños y el ilustrar con imágenes sus textos escolares, siendo el primero en utilizar los materiales audiovisuales que ahora son esenciales en la educación y de la organización escolar que hoy se conoce.

Su meta fue reformar el todo de la humanidad de tal manera que nunca pudo limitar sus esfuerzos solamente a reformar la enseñanza del latín, ni satisfacer meramente con la matemática o la geometría, en el cientifismo que se desarrollaba en su tiempo.

Su Pansofía no sólo fue una teoría del conocimiento sino también un camino hacía la sabiduría de la vida que incluía no únicamente el conocimiento del mundo entero sino también el conocimiento de parte del mundo, esto era, el conocimiento del hombre total. Contenía elementos morales, sociales, religiosos y principios para la reforma del mundo, la educación general que ofrecía el camino hacia el sentido de la vida en la filosofía del hombre y se sus relaciones con el mundo, y el conocimiento especializado que formaban una cultura integrada.

Comenio no fue un investigador dentro de la naturaleza, sino que la naturaleza formaba una parte muy importante del mundo y el hombre debería considerar sus relaciones con ésta cuidadosamente. Si bien no consideró el papel del hombre únicamente como el amo de la naturaleza, éste debería convertirse en el señor de sí mismo. Siendo así, para la educación esto significó, que la teoría y práctica educativas se basarían en una filosofía del hombre y del mundo, por lo que para aprender y enseñar recomendó proceder de lo conocido a lo desconocido, desde lo simple a lo complejo, etc.
En su concepto del hombre lo consideró como una criatura compleja y por lo tanto, que requería una cuidadosa atención en el mundo, consideró la libertad como parte de la esencia de la humanidad, de tal manera que negarla era hacer violencia contra la misma sustancia de la naturaleza humana, aunque también consideró que la libertad no formaba un todo, que ésta podía ser arbitraria y pervertirse hacia la anarquía. La voluntad formaba una unidad dentro de los procesos mentales, dependiente de los sentidos, la razón, las emociones, la conciencia y sus relaciones y de la interrelación de todos ellos y la voluntad.

Para Comenio el hombre no solamente era un animal racional sino también un animal libre de actuar; esto es, sus acciones individuales y sociales eran los criterios de sus potencialidades, incluidas las de su intelecto. Por otra parte, juiciosamente advirtió acerca del peligro de la unilateralidad, la parcialidad e irrespeto por el hombre en su desarrollo individual y social. Su empresa de realizar una síntesis de la tradición y de los elementos de lo moderno, lo colocaron a menudo en una coyuntura difícil, aún así desarrolló principios significativos, los que volcados al escribir una gran didáctica y sus tratados especiales contribuyeron a crear una ciencia de la educación y una teoría de la didáctica, considerados como disciplinas autónomas.

Al proponer la determinación del saber necesario para la vida futura, Comenio introduce a la teoría educativa dos criterios que tienen validez hasta hoy. En el marco de la educación se deben transmitir los conocimientos relevantes de una parte para la vida actual de los educandos, y de otra parte para su futuro. El punto de vista de la necesidad está inseparablemente unido a la pregunta por la selección de los contenidos y valores correctos de la 
educación y la enseñanza y con ello a la pregunta por los criterios de esta selección y su fundamentación. La enseñanza y la escuela en Comenio quedaron así ligadas a la verdad pero también a la utilidad.

Con la estructuración y sistematización, antes mencionada, hizo que la pedagogía en la didáctica magna y en sus otras obras sobre este aspecto, reivindicará la labor de los educadores que era considerada como un oficio para los que no podían desarrollar carrera de alguna ciencia, pues concebía a la pedagogía ya no como un arte tutelar sino como una ciencia que estaba basada en principios científicos.

Como crítica a los métodos de enseñanza duros que sólo despertaban el terror de los alumnos para con el conocimiento y que además destrozaba ingenios, Comenio planteó un método práctico de aprender haciendo que los conocimientos se infiltraran e infundiesen suavemente, llevando al entendimiento la verdadera esencia de las cosas e instrumentos acerca de los fundamentos, razones y fines de lo más importante que existiese, contrario a esto, como método se utilizaba, el uso de la memoria de la palabra y no la de la experiencia; así Comenio insta a formar, primero, el entendimiento de las cosas, luego de la memoria y por último la lengua y las manos.

Su concepción paidocéntrica de la educación pone todos los componentes educativos al servicio del aprendiz, estableciendo un paradigma, ya que anteriormente al alumno no se le daba importancia, siendo considerado como simple receptor-pasivo del conocimiento.

Comenio también aporta de manera explicativa la necesidad de lo que hoy llamamos lineamientos curriculares, concluye en uno de sus fundamentos que todo cuanto se ha de aprender debe escalonarse conforme a los grados de la edad, de tal manera que no se proponga nada al educando que no esté en condiciones de recibir.

Con base en uno de sus principios, extraño para la época, decía que se debía reunir en las escuelas a toda la juventud de uno $u$ otro sexo, planteando la igualdad de géneros considerando a la mujer como igualmente dotada de entendimiento ágil y capaz de la ciencia, así como destinada a elevadas misiones y no entendiendo por qué razón se les aparta del conocimiento de las ciencias.

Otro magnífico aporte consiste en haber trazado un ámbito diferente para aplicar el método. Comenio hizo un rompimiento con aquella práctica donde el conocimiento se adquiría del discurso de los clásicos y situó al niño y al joven como observadores de la naturaleza hablando de las cosas en su propia lengua materna; reconoció para el maestro el arte de enseñar y un espacio bien delimitado para hacerlo: la escuela. El maestro ya no conduciría a los alumnos a los autores como el receptáculo donde podían beber el conocimiento; los conduciría, a través del método, al discurso tratando de anudar en éste las palabras y las cosas.

En su didáctica magna no sólo encontramos redefiniciones del discurso sobre la enseñanza sino también prescripciones para el funcionamiento del saber que reordena. La finalidad de enseñar será aprender no sólo la virtud, sino también conocimientos útiles para la vida. Toda la normatividad introducida por la didáctica magna gira en torno al método cuyo funcionamiento debe darse en una institución específica, la escuela, a tal punto que puede afirmarse que método y escuela son inseparables en su pensamiento. En torno a este gran objeto, los conceptos y la normatividad se refieren 
a tres aspectos particulares: el niño, el maestro, la escuela, sometidos a un fin que expresa el concepto de educación. Enseñar se debe a una disposición de tres cosas: tiempo, objeto y método. Así como la naturaleza es única, igual que Dios, así también el método como imitación de la naturaleza debe ser único, desplegándose entre enseñar-aprender, leer-escribir, palabras-cosas.

Así el maestro no sólo debe encarnar el método de enseñanza, sino él como modelo para sus alumnos, debe dar una doble exaltación autoritaria, dependencia y sumisión pasiva.

Comenio centra sus esfuerzos en un modelo pedagógico para reglamentar y prescribir qué se debe, cómo y cuándo enseñar, dando fundamental importancia al niño como objeto del acto educativo al que se le debe estimular positivamente para que ame el conocimiento, dado éste de manera metódica, sencilla y primordialmente que aprenda haciendo, es decir, activando todos sus sentidos.

Quería que toda la humanidad fuese una sola familia, con una lengua común, una misma educación y un sólo gobierno. Comenio «consideraba a la educación como uno de los medios más importantes para establecer una mejor comprensión de los pueblos» (ONU, Resolución 2412).

La UNESCO y la ONU reconocen sus importantes aportaciones educativas y lo proclaman padre de la pedagogía. Aún después de cumplirse más de tres siglos de su muerte sus tesis educativas todavía tienen vigencia.

\section{BIBLIOGRAFÍA}

Juan Amos Comenio Prefacio de Jean Piaget. Páginas Escogidas. UNESCO Edición A-Z. 